\title{
Investigation Of The Relationship Between Healthy Lifestyle Behavior Of Health Professionals And Use Of Health Care Services: A Research On Attitudes For Vaccine Applications
}

\author{
Fuat YALMAN ${ }^{1}$, Murat BAYAT ${ }^{2}$
}

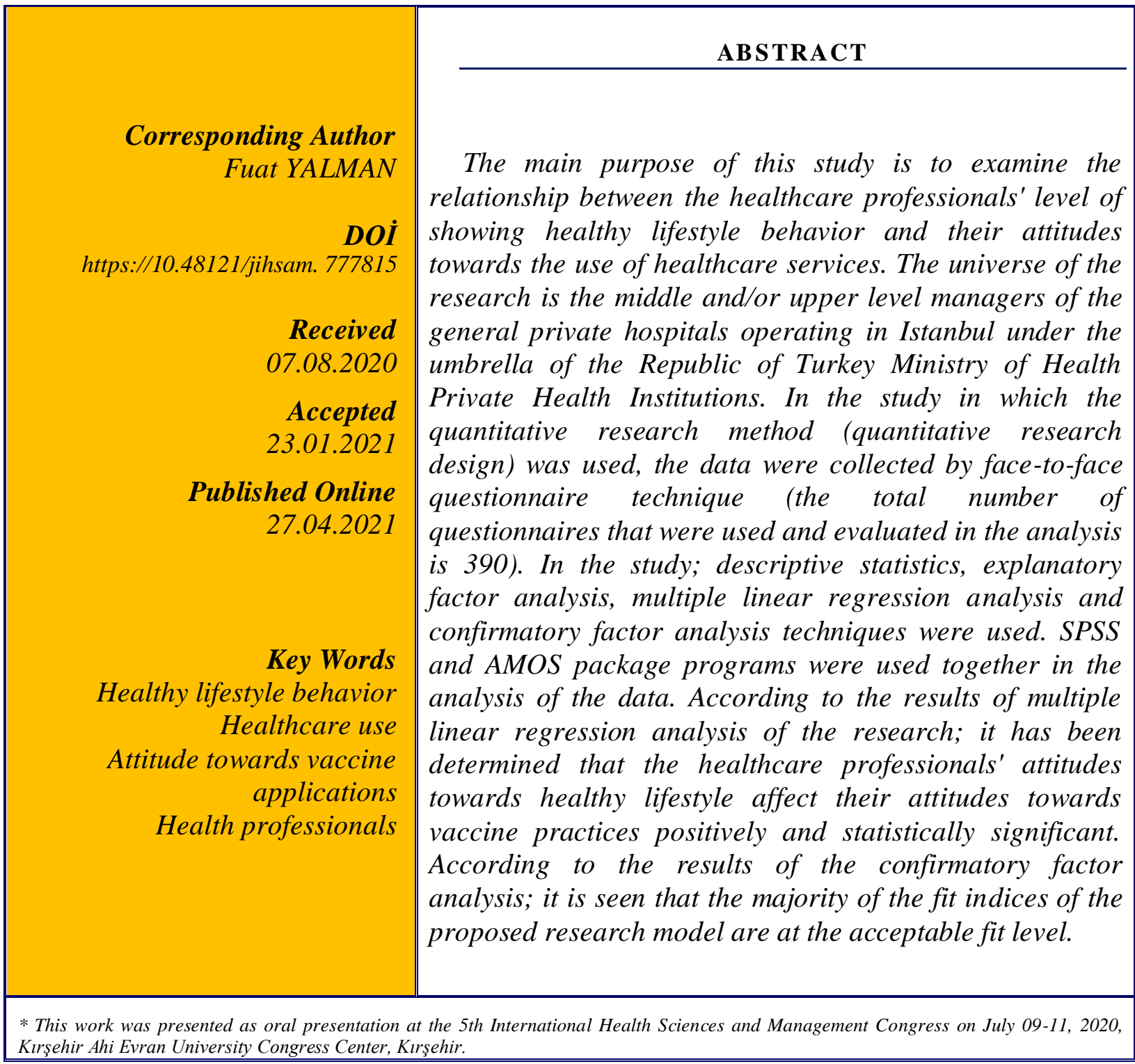

1 Assist. Prof. Dr., Düzce University, fuatyalman@duzce.edu.tr (ORCID: 0000-0002-1041-1837)

Assist. Prof. Dr., Düzce University, muratbayat@duzce.edu.tr (ORCID: 0000-0003-0029-948X) 


\section{INTRODUCTION}

The primary purpose of health services and the primary responsibility of health professionals is to work and ensure that people continue to live and stay healthy and to avoid illness. Increasing the healthcare literacy level is the fundamental strategy in order to decrease the mortality and morbidity depend on planning and delivery of healthcare services and resource expenditure. A person's illness is also a problem for the family and the community they live with, as well as the person who is sick. For this reason, the failure of a person to receive treatment when necessary or to protect herself from diseases cannot be regarded as the problem of that person alone. However, in order to increase the health literacy level of a society, people living in the same society must support each other together in a sense of responsibility and solidarity.

One of the most important public health practices carried out in terms of maintaining health and preventing infectious diseases is the vaccination applications. In our country, vaccines are mostly applied in childhood, adult vaccines are neglected and the necessary importance is not given to adult vaccination. The return on investment and health outcome of childhood vaccination programs are quite high. The main goals of vaccination are to reduce the risks of disease, disability, death and to maintain the overall health status of the society. The incidence of most vaccine-preventable diseases in the 20th century has been reduced by more than $99 \%$ as a result of vaccination practices, while some (smallpox) have been completely eliminated. Also, vaccines, like every medicinal product, have anticipated and undesirable effects after vaccination. Its benefit is 100-1000 times more than possible damage. Vaccines are applied to protect the vaccinated, and if the population is vaccinated at a very high rate and widespread, those who have not reached the age of vaccination and those with an anti-vaccination disease maintain their immunity level.

In addition, it is useful and necessary to apply the vaccines to our children in the most appropriate and wide-ranging framework, with the awareness that healthy, educated and carefully trained children will be the most important source and power of the country, considering adults as the future of a country. It is important that every person in the society and the society are aware of their responsibility for their own health, and cooperate with the relevant people to consider and realize acceptable ways and methods to improve their health. According to the data of the World Health Organization (WHO), Over 100 million children are vaccinated before one year old and 2.5 million children are protected from death each year depending on the vaccine applications.

\section{Literature Review}

\subsection{Healthy Lifestyle Behavior}

The importance of healthy lifestyle behaviors is well known for the promotion of cardiovascular health, reducing risk, prevention and management of diseases. Health behaviors such as dietary intake, physical activity, inactivity, smoking and alcohol consumption have been emphasized as universal healthy lifestyle behaviors and have been adopted as a central component of evidence-based guidelines for children, adolescents and adults from various populations. At the same time, healthy lifestyle behaviors and therapeutic lifestyle changes were reemphasized as the main variable in promoting cardiovascular health and reducing cardiovascular risk, respectively (Zachariah and de Ferranti, 2013).

Healthy lifestyle behaviors such as regular fruit and vegetable consumption, regular physical activity and having a healthy weight provide significant protection against many chronic conditions such as cancer, cardiovascular diseases, diabetes and stroke (Millen et al., 2016). Some behavioral changes acquired in lifestyle; has shown to reduce blood pressure, blood cholesterol, triglycerides, blood sugar and cardiometabolic risk by controlling the body weight (Knowler et al., 2002; Eckel et al., 2014).

Healthy lifestyle behavior is the activity that individuals undertake to protect or improve their health, prevent health problems or achieve a positive body image. Healthy lifestyle behavior is not only limited to healthy people trying to stay healthy, but also includes people who are physically disabled and have chronic diseases that try to control or minimize their ailments through positive forms of healthy behavior, such as diet, exercise and avoiding smoking (Cockerham, 2014).

Conner and Norman (1996) defined healthy lifestyle behavior as any activity carried out to prevent or detect disease or increase health and well-being. Gochman (1997) on the other hand, in his "healthy behavior research handbook" expressed healthy behaviors; as behavior patterns, actions and habits related to health care, health restoration and health promotion. Behaviors in this definition include the use of medical services (doctor visits, vaccination, screening), compliance with medical regimens (diet, diabetes, antihypertensive regimens) and self-directed 
health behaviors (diet, exercise, smoking, alcohol consumption).

Some studies in the literature have examined the relationship between healthy lifestyle behavior and health outcomes, and have shown that healthy lifestyle behaviors play an important role in reducing both morbidity and mortality rates (Blaxter, 1990). In one of the first studies of such; It has been observed found a positive correlation between seven major lifestyles (lower smoking, moderate alcohol consumption, 7-8 hours of sleep during the night, regular exercise, maintaining the desired body weight, avoiding snacks, and regular breakfast) and lower morbidity and higher long-term survival (Belloc and Breslow, 1972). Healthy lifestyle behaviors also affect the quality of life of individuals by delaying the onset of chronic disease and prolonging its active life (Conner, 2015).

\subsection{Vaccine Application}

Vaccines are the most effective method of protecting child and adult health and preventing infectious diseases in terms of cost and reliability (Arisoy et al., 2015). It is known that approximately 23 million children die in the world, especially in less developed countries from diseases that can be prevented by vaccination every year. It is thought that 1.5 million of these deaths can be prevented if the global vaccination coverage is increased. The main target of immunization services is to prevent the emergence of vaccine-protected diseases in children and infants, and to reduce the morbidity and mortality due to infections. The main goal of this service is not to leave children without vaccines (World Health Organization, 2019).

One of the most important public health practices carried out in terms of maintaining health and preventing infectious diseases is the vaccination applications (U.S. Department of Health \& Human Services, 2020). In our country, vaccines are mostly applied in childhood, adult vaccines are neglected and the necessary importance is not given to adult vaccination. The return on investment and health outcome of childhood vaccination programs are quite high (WHO, 2009).

It is especially important to protect the elderly population with vaccines against life-threatening diseases. In addition, the costs incurred due to the inability to prevent vaccine-preventable diseases in adults create a significant economic burden in society.
In this context, in addition to the medical load, there may be indirect costs that are more difficult to calculate and sometimes overlooked, such as loss of labor, travel and companion costs, and the costs of the relatives of the patients. More than 50,000 adult patients die each year from vaccine-preventable disease, and thousands more than this complain of serious diseases. Therefore, regular provision of vaccination services will reduce the diseases and complications associated with vaccination and mortality rates (Adult Immunization Guide, 2016).

2.3. Relationship between Healthy Lifestyle Behavior and Attitudes for Vaccine Application

Healthy lifestyle behaviors are defined as the individual's behaviors to protect against diseases and maintain a healthy lifestyle in the society. Healthy living behaviors are a way of life and if the individual can acquire these behaviors, he / she can maintain his / her health status, improve his/her health status, improve the quality of life and cope with many diseases and stresses easily (Karaca and Özkan, 2016).

Healthy lifestyle, which is an important element of improving health, includes behaviors that increase the level of well-being throughout life as well as protection from diseases. Acquiring healthy lifestyle behaviors are extremely important in preventing the occurrence of chronic diseases, increasing the quality of life in case of chronic disease, ensuring a healthy life and aging (Cindaş, 2001). Today, it is known that lifestyle elements such as exercise, diet, smoking and stress affect health and risk of cardiovascular disease, and morbidity and mortality in chronic diseases such as cancer, heart disease, hypertension and diabetes can be significantly reduced with lifestyle changes (Ferguson, 1998). In addition, studies have shown that there is a relationship between lifestyle and health status, health care use and health care systems (Fleming and Marshall, 2008).

The individual, who transforms healthy lifestyle behaviors into a lifestyle, can maintain his well-being and improve his health. Therefore, the development and maintenance of healthy lifestyle behaviors are the foundation of health and disease protection. This situation reveals the importance of practices for the development of life styles, which are the most important factors in the prevention of diseases and health promotion (Zaybak and Fadiloğlu, 2004; Ayaz et al., 2005). 


\section{MATERIAL AND METHOD}

\subsection{Purpose and Scope of the Research}

The main purpose of this study is to examine the relationship between the healthcare professionals' level of showing healthy lifestyle behaviors and their attitudes towards the use of healthcare services. However, determining the participants ' attitudes towards healthy lifestyle and vaccine practices constitutes the sub-objectives of the research. The study is descriptive and cross-sectional. Also in the study; quantitative research method has been used since it is thought that the validity and reliability of the research results can be fully ensured by considering the purpose of the research, the problem of the research and the subject of the research.

\subsection{Population and Sample of the Research}

The universe of the research is the middle and/or upper level managers of the private hospitals operating in Istanbul under the umbrella of the Republic of Turkey Ministry of Health. In the study in which the quantitative research method (quantitative research design) was used, the data were collected between January and March 2019 using face-to-face questionnaire technique (the total number of questionnaires evaluated and used in the analysis of the data is 390).

\subsection{Model and Hypothesis of the Research}

As a result of the literature review carried out during the model development phase, similar model studies were examined and the conceptual / theoretical model of the research was created. The relationship between the healthcare professionals' behaviors and their attitudes towards vaccine practices constitutes the subject of the research. The statement "Healthy lifestyle behavior level has an effect on attitude towards vaccine applications" constitutes the thesis of the research. The conceptual model of the research, the relationship between the basic variables of the research (healthy behavior level, rational drug use level) are discussed. The relationship between the conceptual

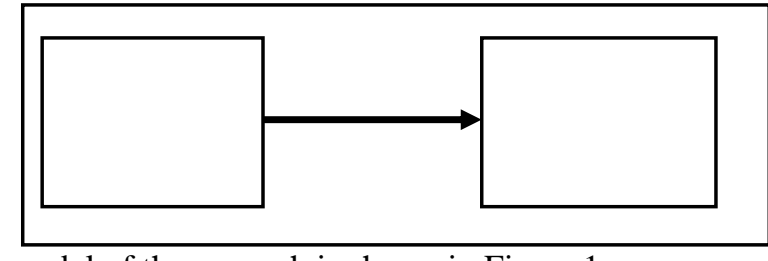

model of the research is shown in Figure 1,

Figure 1: Conceptual Model of the Research

In the literature, individuals with a sufficient level of health knowledge and healthy lifestyle behavior level have been emphasized that they had a high level of health literacy, they are the ones who benefit from health services effectively and cause the quality of life, health service quality and patient loyalty to increase and also the cost of health services to decrease. On the other hand, individuals with insufficient level of health knowledge and healthy behaviors are more likely to have sickness risks compared to others, have lower levels of understanding of treatment methods, less benefit from healthcare services, higher frequency of hospitalization, as well as higher healthcare costs (Kanj and Mitic, 2009; Baur et al., 2017). The basic hypothesis developed in this direction is as follows:

$\mathbf{H}_{1:}$ "The level of healthcare professionals' behaviors in a healthy lifestyle affects their attitudes towards vaccine practices statistically significant and positive."

As a result of the literature research carried out, while similar studies are encountered in the health sectors in relation to the relationships between some variables in the research model; no studies involving specific hypothesis discussions among the specified variables in the model have been found. Therefore, in order to reveal the interactions between the variables, a hypothesis has been developed based on the literature discussions in the second section.

\subsection{Data Collection Tool and Analysis Methods}

Descriptive and cross-sectional data were collected by using questionnaire technique in the study. A detailed literature review was conducted for the preparation of the research questionnaire and, in the light of the obtained documents and information, previously developed model studies (in different or similar fields) related to the variables included in the research were selected and harmonized with the structural features of the health services that constitute the subject of the research. The questionnaire consists of three parts. In the first part, statements about healthy lifestyle behavior level consisting of 47 statements take place. In the second part, while there are expressions to determine the attitudes towards vaccination practices consisting of 40 propositions; in the last part, there are statements about the sociodemographic characteristics of the participants. In the study, convenient sampling method was preferred. In the study; descriptive statistics, explanatory factor analysis (AFA), confirmatory factor analysis (CFA) and path (analysis) techniques were used. SPSS and AMOS package programs were used together in the analysis of the data. 


\section{FINDINGS}

The data obtained in the findings section were evaluated through SPSS and AMOS package programs.

\subsection{Normality Distribution of Research Data}

In the research, Kolmogorov-Smirnov normality test which is the normal distribution test, was applied and as a result, it was seen that the data did not distribute normally. In large sample data (where $n>$ 400), even if the test results show that the normality requirement is not met, this is of little importance in practice.

\subsection{Reliability of Research Data}

In the study, reliability measurement was made by calculating the Cronbach's Alpha coefficient for each structure. Healthy lifestyle behavior factors, which constitute the variables of the study, were subjected to reliability analysis with 47 questions, and attitude factors towards vaccine applications with 40 questions. Reliability coefficients for variables are given in Table 1.

Table 1. Reliability Analysis Results

\begin{tabular}{lc}
\hline Variable names & $\begin{array}{c}\text { Cronbach's } \\
\text { Alpha } \\
\text { Coefficient }\end{array}$ \\
\hline $\begin{array}{l}\text { Healthy Lifestyle } \\
\text { Behaviour }\end{array}$ & 0,937 \\
\hline $\begin{array}{l}\text { Attitude towards Vaccine } \\
\text { Practices }\end{array}$ & 0,949 \\
\hline Survey Reliability Total & $\mathbf{0 , 9 5 0}$ \\
\hline
\end{tabular}

Therefore, it is seen that the reliability of the research is quite high in considering all the dimensions.

\subsection{Demographic Findings}

Table 2. General Profile of the Participants

\begin{tabular}{lcclcc}
\hline Gender & Frequency & Rate & Age & Frequency & Rate \\
\hline Male & 148 & $3, .9$ & $18-25$ & 129 & 33,1 \\
\hline Woman & 242 & 62,1 & $26-35$ & 210 & 53,8 \\
\hline Total & 390 & 100 & $36-45$ & 36 & 9,2 \\
\hline Education status & Frequency & Rate & $46-55$ & 14 & 3,6 \\
\hline Primary school & 1 & 0,3 & 56 and over & 1 & 0,3 \\
\hline Middle School & 1 & 0,3 & Total & 390 & 100 \\
\hline High school & 42 & 10,8 & Profession & Frequency & Rate \\
\hline University & 328 & 84,1 & Senior manager & 139 & 35,1 \\
\hline Master / PhD & 18 & 4,6 & Mid-level manager & 251 & 64,4 \\
\hline Total & 390 & 100 & Total & 390 & 100 \\
\hline
\end{tabular}

When Table 2 is examined in detail, information about the gender, age, educational status and occupation of the individuals participating in the research are given. $62 \%$ of the individuals participating in the study are women, $84 \%$ are university graduates, $64 \%$ are middle-age people and $64,4 \%$ are middle-level managers.

\subsection{Findings Related to Explanatory (Exploratory) Factor Analysis}

An explanatory factor analysis was performed on the data that constituted the attitudes of the participants towards healthy lifestyle behavior and vaccine applications. The analyzes carried out in this direction are given below (Table 3 and Table 4). 
Table 3. Health Lifestyle Behavior-Explanatory Factor Analysis Results

\begin{tabular}{|c|c|c|c|c|}
\hline Factors & Variables & Factor Loads & $\begin{array}{c}\text { Announced } \\
\text { Variance }\end{array}$ & $\begin{array}{c}\text { Core } \\
\text { Value }\end{array}$ \\
\hline \multirow{10}{*}{ Health Anxiety } & HLB45 &, 748 & \multirow{10}{*}{29,076} & \multirow{10}{*}{11,340} \\
\hline & HLB 40 &, 737 & & \\
\hline & HLB44 & ,661 & & \\
\hline & HLB36 & 620 & & \\
\hline & HLB39 &, 589 & & \\
\hline & HLB37 &, 579 & & \\
\hline & HLB46 &, 572 & & \\
\hline & HLB41 &, 542 & & \\
\hline & HLB22 & ,482 & & \\
\hline & HLB43 & ,436 & & \\
\hline \multirow{4}{*}{ Physical Activity } & HLB10 & ,802 & \multirow{4}{*}{7,664} & \multirow{4}{*}{2,989} \\
\hline & HLB4 & ,769 & & \\
\hline & HLB28 & ,715 & & \\
\hline & HLB16 & 674 & & \\
\hline \multirow{5}{*}{ Health Responsibility } & HLB27 & ,791 & \multirow{5}{*}{6,026} & \multirow{5}{*}{2,350} \\
\hline & HLB21 & ,790 & & \\
\hline & HLB15 &, 751 & & \\
\hline & HLB3 &, 582 & & \\
\hline & HLB33 & ,466 & & \\
\hline \multirow{6}{*}{ Spiritual Development } & HLB24 & ,728 & \multirow{6}{*}{4,786} & \multirow{6}{*}{1,867} \\
\hline & HLB 18 & ,649 & & \\
\hline & HLB23 &, 588 & & \\
\hline & HLB12 &, 585 & & \\
\hline & HLB6 & ,478 & & \\
\hline & HLB30 & ,462 & & \\
\hline \multirow{3}{*}{ Stress Management } & HLB5 & ,730 & \multirow{3}{*}{4,239} & \multirow{3}{*}{1,653} \\
\hline & HLB29 & ,613 & & \\
\hline & HLB11 &, 593 & & \\
\hline \multirow{4}{*}{ Interpersonal Relations } & HLB19 & 640 & \multirow{4}{*}{3,585} & \multirow{4}{*}{1,398} \\
\hline & HLB35 & ,566 & & \\
\hline & HLB34 &, 507 & & \\
\hline & HLB13 & ,445 & & \\
\hline \multirow{3}{*}{ Balanced diet } & HLB32 & ,780 & \multirow{3}{*}{3,073} & \multirow{3}{*}{1,198} \\
\hline & HLB28 & 655 & & \\
\hline & HLB26 & ,625 & & \\
\hline \multirow{2}{*}{ Compatibility } & HLB7 & ,732 & \multirow{2}{*}{2,828} & \multirow{2}{*}{1,103} \\
\hline & HLB1 & ,666 & & \\
\hline \multirow{6}{*}{ Evaluation Criteria } & Kaiser-Mej & -Olkin Mea sure & ampling Adeq & 865 \\
\hline & Approx. $\mathrm{Cl}$ & qquare: 7092,513 & & \\
\hline & Barlett's Te & of Sphericity: 0, & & \\
\hline & Extraction & thod: Principal & onents & \\
\hline & Rotation M & od: Varimax & & \\
\hline & Explained & iance Total: 61 , & & \\
\hline
\end{tabular}

The KMO value of the data analyzed to determine the sub-variables of the Health Lifestyle Behavior factors and the Bartlett's test result seem to be acceptable for factor analysis (KMO value 0,865 and Bartlett's Test result $\mathrm{p}<0,001)$. On the other hand, principal components analysis and varimax rotation technique were used for factor analysis. As a result of the explanatory factor analysis performed, expressions with low equivalence and less than 0,40 were completely removed from the scale. On the other hand, factors were renamed considering the 
contents of the items, factor loads and names in the $\mid$ literature.

Table 4. Attitudes-Explanatory Factor Analysis Results for Vaccine Applications

\begin{tabular}{|c|c|c|c|c|}
\hline Factors & Variables & Factor Loads & $\begin{array}{l}\text { Announced } \\
\text { Variance }\end{array}$ & $\begin{array}{l}\text { Core } \\
\text { Value }\end{array}$ \\
\hline \multirow{9}{*}{ Risks / Benefits } & AVP15 &, 755 & \multirow{9}{*}{36,113} & \multirow{9}{*}{13,723} \\
\hline & AVP19 &, 717 & & \\
\hline & AVP20 & 678 & & \\
\hline & AVP29 & 635 & & \\
\hline & AVP30 & 635 & & \\
\hline & AVP31 & 614 & & \\
\hline & AVP34 &, 568 & & \\
\hline & AVP35 &, 538 & & \\
\hline & AVP36 &, 518 & & \\
\hline \multirow{8}{*}{ Communication and Media Tools } & AVP21 & ,808 & \multirow{8}{*}{11,342} & \multirow{8}{*}{4,310} \\
\hline & AVP22 &, 707 & & \\
\hline & AVP23 & 693 & & \\
\hline & AVP24 & ,684 & & \\
\hline & AVP25 & ,649 & & \\
\hline & AVP26 & 613 & & \\
\hline & AVP27 &, 594 & & \\
\hline & AVP28 &, 507 & & \\
\hline \multirow{6}{*}{$\begin{array}{l}\text { Beliefs and Approaches to Health and } \\
\text { Preventive Practices }\end{array}$} & AVP1 & ,827 & \multirow{6}{*}{4,855} & \multirow{6}{*}{1,845} \\
\hline & AVP2 & 822 & & \\
\hline & AVP3 &, 756 & & \\
\hline & AVP4 &, 726 & & \\
\hline & AVP6 & ,621 & & \\
\hline & AVP37 &, 542 & & \\
\hline \multirow{3}{*}{ The Role of Healthcare Professionals } & AVP11 &, 835 & \multirow{3}{*}{4,375} & \multirow{3}{*}{1,662} \\
\hline & AVP12 &, 812 & & \\
\hline & AVP13 & 684 & & \\
\hline \multirow{3}{*}{ Social Norms } & AVP16 & ,876 & \multirow{3}{*}{3,796} & \multirow{3}{*}{1,443} \\
\hline & AVP17 &, 852 & & \\
\hline & AVP18 & ,844 & & \\
\hline \multirow{3}{*}{ Health System and Trust Providers } & AVP38 &, 734 & \multirow{3}{*}{3,592} & \multirow{3}{*}{1,365} \\
\hline & AVP39 & ,726 & & \\
\hline & AVP40 &, 565 & & \\
\hline \multirow{3}{*}{ People Effective on Society } & AVP8 &, 705 & \multirow{3}{*}{2,948} & \multirow{3}{*}{1,120} \\
\hline & AVP9 & 647 & & \\
\hline & AVP10 &, 502 & & \\
\hline \multirow{2}{*}{ Cost } & AVP32 &, 823 & \multirow{2}{*}{2,809} & \multirow{2}{*}{1,068} \\
\hline & AVP33 & ,752 & & \\
\hline \multirow{5}{*}{ Evaluation Criteria } & $\begin{array}{l}\text { Kaiser-Me } \\
\text { Approx. C }\end{array}$ & $\begin{array}{l}\text { lkin Mea sure of } \\
\text { uare: } 10113,058\end{array}$ & Impling Adequ & 0,896 \\
\hline & Barlett's Te & Sphericity: 0,00 & & \\
\hline & Extraction & od: Principal Co & onents & \\
\hline & Rotation $\mathrm{N}$ & d: Varimax & & \\
\hline & Explained & nce Total: 69,83 & & \\
\hline
\end{tabular}

The KMO value of the data analyzed in order to determine the sub-variables of attitude factors for vaccine applications and the Bartlett test result seem to be acceptable for factor analysis (KMO value 0,896 
and Bartlett's Test result $\mathrm{p}<0,001)$. On the other hand, principal components analysis and varimax rotation technique were used for factor analysis. As a result of the explanatory factor analysis performed, expressions with low equivalence and less than 0.40 were completely removed from the scale. On the other hand, factors were renamed considering the contents of the items, factor loads and names in the literature.
Descriptive statistics about the variables obtained were examined after the explanatory factor analysis and frequency analysis. Information about the averages, standard deviations, reliability coefficients, question numbers and scale levels used for each variable are presented in Table 5.

Table 5. Descriptive/Descriptive Statistics Related to Factors

\begin{tabular}{clcccc}
\hline Dimensions & Factors & N & Mean & Std. Dev. & Variance \\
\hline & Risks / Benefits & 390 & 4,1158 &, 68734 &, 472 \\
Attitude & Communication and Media Tools & 390 & 3,4673 &, 83252 &, 693 \\
Bowards Vaccineliefs and Approaches to Health and & Preventive Practices & 390 & 4,2878 &, 68514 &, 469 \\
Practices & The Role of Healthcare Professionals & 390 & 3,7584 & 1,01334 & 1,027 \\
& Social Norms & 390 & 2,2860 & 1,24782 & 1,557 \\
& Health System and Trust Providers & 390 & 4,0465 &, 86896 &, 755 \\
& People Effective on Society & 390 & 3,5743 &, 91000 &, 828 \\
& Cost & 390 & 3,6468 & 1,13130 & 1,280 \\
\hline \multirow{5}{*}{ Healthy } & Health Anxiety & 390 & 3,3040 &, 83127 &, 691 \\
Behaviour & Physical Activity & 390 & 3,2768 & 1,01354 & 1,027 \\
& Health Responsibility & 390 & 3,8768 &, 80197 &, 643 \\
& Spiritual Development & 390 & 3,8596 &, 67673 &, 458 \\
& Stress Management & 390 & 3,6404 &, 82571 &, 682 \\
& Interpersonal Relations & 390 & 3,9889 &, 70529 &, 497 \\
& Balanced diet & 390 & 3,9911 &, 75560 &, 571 \\
& Compatibility & 390 & 4,2775 &, 71740 &, 515 \\
\hline
\end{tabular}

When Table 5 is analyzed, it is seen that the variable "Compatibility" (Av: 4,277) has the highest average among healthy lifestyle behavior factors. The reliability coefficients higher than 0.60 indicate that the scales used in the study are reliable. Similarly, among the attitude factors towards vaccine applications, the highest average variable is seen as "Beliefs and Approaches to Health and Preventive Practices" (Avg: 4,287). The reliability coefficients higher than 0,60 indicate that the scales used in the study are reliable.

\subsection{Findings Related to Multiple Regression Analysis \\ In this section, the relationships between the variables are revealed by making multiple regression analysis to the attitude scales of healthy lifestyle behavior and vaccine applications with SPSS package program.}

\subsubsection{Results of Multiple Regression Analysis}

In the research model; factors (latent factors) such as Health Anxiety, Physical Activity, Health Responsibility, Spiritual Development, Stress Management, Interpersonal Relationships, Balanced Nutrition, Compliance and Risks / Benefits, Communication and Media Tools, Beliefs and Approaches to Health and Preventive Practices, the Role of Health Workers, Social Norms, Health System and Trust in Providers, Cost, Community Affected Persons and causal relationships between these factors are assumed to be explained. Firstly, the effects of "healthy lifestyle behavior level of the society on the attitudes towards vaccine applications" were examined within the framework of causality relationship. 
Table 6. Healthy Lifestyle Behavior Factors-Risks/Benefits Multiple Regression Analysis Results

\begin{tabular}{lccccc}
\hline Variables & $\mathbf{B}$ & Std. Error & $\boldsymbol{\beta}$ & $\mathbf{t}$ & $\mathbf{p}$ \\
\hline (Fix) & 1,506 &, 248 & - & 6,078 &, 000 \\
Health Anxiety &,- 147 &, 056 &,- 176 & $-2,632$ &, 009 \\
Physical Activity &,- 076 &, 041 &,- 110 & $-1,864$ &, 063 \\
Health Responsibility &, 170 &, 051 &, 198 & 3,351 &, $\mathbf{0 0 1}$ \\
Spiritual Development &,- 015 &, 062 &,- 015 &,- 246 &, 806 \\
Stress Management &, 005 &, 048 &, 006 &, 110 &, 913 \\
Interpersonal Relations &, 126 &, 064 &, 129 & 1,955 &, 051 \\
Balanced diet &, 256 &, 050 &, 281 & 5,094 & $\mathbf{0 0 0}$ \\
compatibility &, 277 &, 051 &, 284 & 5,375 & $\mathbf{0 0 0}$ \\
\hline
\end{tabular}

Dependent variable: Risks / Benefits R: 0,543 $\mathrm{R}^{2_{2}} 0,295$ p: 0,000

When Table 6 is examined, it is seen that the Risks/Benefits of Health Anxiety, Health Responsibility, Balanced Nutrition, Compliance and vaccination practices are moderately positive bilateral correlations in bilateral relations, and when other variables of the study are taken into consideration, these relationship levels are partially decreased (low correlation). On the other hand, healthy lifestyle behavior together with sub-dimensions give a moderate and significant relationship with the risks / benefits of vaccine applications (R: 0,543, $R^{2}: 0,295$, p: 0,000$)$ and $29 \%$ of the total variance is explained by the level of risks / benefits of vaccine applications.

In Table 7, there are results related to the effect of healthcare professionals' healthy lifestyle behaviors on "Communication and Media Tools", which is one of the sub-dimensions of attitude towards vaccine applications.

Table 7. Healthy Lifestyle Behavior Factors- Communication and Media Tools Multiple Regression Analysis Results

\begin{tabular}{lccccc}
\hline Variables & $\mathbf{B}$ & Std. Error & $\boldsymbol{\beta}$ & $\mathbf{t}$ & $\mathbf{p}$ \\
\hline (Fix) & 1,296 &, 303 & - & 4,278 &, 000 \\
Health Anxiety &, 502 &, 068 &, 510 & 7,329 &, $\mathbf{0 0 0}$ \\
Physical Activity &,- 096 &, 050 &,- 118 & $-1,931$ &, 054 \\
Health Responsibility &,- 042 &, 062 &,- 042 &,- 684 &, 494 \\
Spiritual Development &,- 091 &, 075 &,- 075 & $-1,218$ &, 224 \\
Stress Management &, 028 &, 059 &, 028 &, 473 &, 636 \\
Interpersonal Relations &,- 063 &, 078 &,- 054 &,- 803 &, 423 \\
Balanced diet &, 131 &, 061 &, 121 & 2,145 &, $\mathbf{0 3 3}$ \\
compatibility &, 219 &, 062 &, 190 & 3,509 &, $\mathbf{0 0 1}$ \\
\hline Dependent variable: Communication and Media Tools R: 0,512 & & $\mathrm{R}^{2: 0,262}$ & $\mathrm{p}: 0,000$
\end{tabular}

When Table 7 is examined, it is seen that the role of communication and media tools in Health Anxiety, Balanced Nutrition, Compliance and vaccination practices, there is a moderate positive bilateral correlation in bilateral relations, and when other variables of the study are taken into consideration, these relationship levels are partially decreased (low positive correlation On the other hand, healthy lifestyle behavior sub-dimensions together give a moderate and significant relationship with the role of communication and media tools in vaccine applications (R: $\left.0,512, \mathrm{R}^{2}: 0,262, \mathrm{p}: 0,000\right)$ and the role of communication and media tools in vaccine applications explain $26 \%$ of the total variance.

Table 8 contains the results regarding the effect of healthcare professionals' healthy lifestyle behaviors on "Beliefs and Approaches to Health and Preventive Practices", which is one of the sub-dimensions of attitude towards vaccine practices. 
Table 8. Healthy Lifestyle Behavior Factors- Beliefs and Approaches to Health and Preventive Practices Multiple Regression Analysis Results

\begin{tabular}{lccccc}
\hline Variables & $\mathbf{B}$ & Std. Error & $\boldsymbol{\beta}$ & $\mathbf{t}$ & $\mathbf{p}$ \\
\hline (Fix) & 1,705 &, 254 & - & 6,702 &, 000 \\
Health Anxiety &,- 114 &, 058 &,- 136 & $-1,981$ & $\mathbf{0 4 8}$ \\
Physical Activity &,- 060 &, 042 &,- 086 & $-1,420$ &, 156 \\
Health Responsibility &,- 014 &, 052 &,- 017 &,- 274 &, 784 \\
Spiritual Development &, 071 &, 063 &, 069 & 1,118 &, 264 \\
Stress Management &, 040 &, 050 &, 047 &, 809 &, 419 \\
Interpersonal Relations &, 176 &, 066 &, 179 & 2,659 & $\mathbf{0 0 8}$ \\
Balanced diet &, 182 &, 052 &, 199 & 3,520 & $\mathbf{0 0 0}$ \\
compatibility &, 315 &, 053 &, 321 & 5,944 & $\mathbf{0 0 0}$ \\
\hline
\end{tabular}

Dependent variable: Beliefs and Approaches to Health and Preventive Practices R: 0,506 $\mathrm{R}^{2:}$ 0,256 p:0,000

When Table 8 is examined, beliefs and approaches regarding health and preventive practices about Health Anxiety, Interpersonal Relationships, Balanced Nutrition, Compatibility and vaccine applications, there is a moderate positive bilateral correlation between bilateral relations and when other variables of the study are taken into consideration, these relationship levels are partially decreased ( low level of positive correlation). On the other hand, healthy lifestyle behavior together with subdimensions give a moderate and meaningful relationship with beliefs and approaches about health and preventive practices about vaccine applications (R: $0,506, R^{2}: 0,256$, p: 0,000 ) and $25 \%$ of the total variance is explained by the level of beliefs and approaches to health and preventive practices on vaccine practices.

In Table 9, there are results regarding the effect of healthcare professionals' healthy lifestyle behaviors on "Role of Healthcare Professionals", which is one of the sub-dimensions of attitude towards vaccine practices.

Table 9. Healthy Lifestyle Behavior Factors- Role of Healthcare Professionals Multiple Regression Analysis Results

\begin{tabular}{lccccc}
\hline Variables & $\mathbf{B}$ & Std. Error & $\boldsymbol{\beta}$ & $\mathbf{t}$ & $\mathbf{p}$ \\
\hline (Fix) & 1,450 &, 400 & - & 3,626 &, 000 \\
Health Anxiety &, 129 &, 091 &, 106 & 1,426 &, 155 \\
Physical Activity &,- 059 &, 066 &,- 058 &,- 886 &, 376 \\
Health Responsibility &, 034 &, 082 &, 027 &, 413 &, 680 \\
Spiritual Development &,- 198 &, 100 &,- 133 & $-1,991$ &, $\mathbf{0 4 7}$ \\
Stress Management &, 121 &, 079 &, 098 & 1,540 &, 124 \\
Interpersonal Relations &,- 127 &, 104 &,- 089 & $-1,222$ &, 223 \\
Balanced diet &, 302 &, 082 &, 227 & 3,690 &, $\mathbf{0 0 0}$ \\
compatibility &, 364 &, 083 &, 256 & 4,361 & $\mathbf{0 0 0}$ \\
\hline
\end{tabular}

Dependent variable: Role of Healthcare Professionals

$R: 0,363 \quad R^{2:} 0,132 \quad p: 0,000$

When Table 9 is examined, it is seen that the role of healthcare professionals in Spiritual Development, Balanced Nutrition, Compatibility and vaccine applications is a moderate positive bilateral correlation in bilateral relations, and when other variables of the study are taken into consideration, these relationship levels are partially decreased (low positive correlation).On the other hand, healthy lifestyle behavior together with sub-dimensions give a moderate and significant relationship with the role of healthcare workers in vaccination practices ( $R$ : $\left.0,363, R^{2}: 0,132, p: 0,000\right)$ and the $13 \%$ of the total variance is explained at the level of the role of healthcare workers in vaccine practices. 
In Table 10, there are results regarding the effect of healthcare professionals' healthy lifestyle behaviors on "Social Norms", which is one of the subdimensions of attitude towards vaccine practices.

Table 10. Healthy Lifestyle Behavior Factors- Social Norms Multiple Regression Analysis Results

\begin{tabular}{lccccc}
\hline Variables & $\mathbf{B}$ & Std. Error & $\boldsymbol{\beta}$ & $\mathbf{t}$ & $\mathbf{p}$ \\
\hline (Fix) & 1,852 &, 467 & - & 3,964 &, 000 \\
Health Anxiety &, 958 &, 106 &, 640 & 9,059 &, $\mathbf{0 0 0}$ \\
Physical Activity &,- 124 &, 077 &,- 100 & $-1,610$ &, 108 \\
Health Responsibility &,- 330 &, 096 &,- 216 & $-3,453$ &, $\mathbf{0 0 1}$ \\
Spiritual Development &,- 144 &, 116 &,- 078 & $-1,238$ &, 217 \\
Stress Management &, 055 &, 091 &, 037 &, 608 &, 544 \\
Interpersonal Relations &,- 118 &, 121 &,- 067 &,- 971 &, 332 \\
Balanced diet &,- 020 &, 095 &,- 012 &,- 215 &, 830 \\
Compatibility &,- 035 &, 097 &,- 020 &,- 356 &, 722 \\
\hline
\end{tabular}

Dependent variable: Social Norms

R: 0,463

When Table 10 is examined, it is seen that there is a moderate positive bilateral correlation between Health Anxiety, Health Responsibility and social norms in vaccination practices, and when the other variables of the study are taken into consideration, these relationship levels are partially decreased (low positive correlation). On the other hand, healthy lifestyle behavior together with sub-dimensions give a moderate and meaningful relationship with the role of social norms in vaccine applications (R: $0,463, R^{2}$ :
$\mathrm{R}^{2:} 0,214 \quad \mathrm{p}: 0,000$

$0,214, \mathrm{p}: 0,000)$ and $21 \%$ of the total variance is explained by the level of the role of social norms in vaccine practices.

Table 11 contains the results regarding the effect of healthcare professionals' healthy lifestyle behaviors on "Health System and Provider Trust", which is one of the sub-dimensions of attitude towards vaccine applications.

Table 11. Healthy Lifestyle Behavior Factors-Health System and Trust Providers Multiple Regression Analysis Results

\begin{tabular}{lccccc}
\hline Variables & $\mathbf{B}$ & Std. Error & $\boldsymbol{\beta}$ & $\mathbf{t}$ & $\mathbf{p}$ \\
\hline (Fix) & 1,595 &, 340 & - & 4,697 &, 000 \\
Health Anxiety &, 145 &, 077 &, 137 & 1,890 &, 060 \\
Physical Activity &,- 163 &, 056 &,- 186 & $-2,910$ &, $\mathbf{0 0 4}$ \\
Health Responsibility &, 053 &, 070 &, 049 &, 765 &, 445 \\
Spiritual Development &,- 043 &, 085 &,- 033 &,- 512 &, 609 \\
Stress Management &, 044 &, 066 &, 041 &, 663 &, 508 \\
Interpersonal Relations &, 174 &, 088 &, 140 & 1,968 &, $\mathbf{0 5 0}$ \\
Balanced diet &, 111 &, 069 &, 096 & 1,609 &, 109 \\
Compatibility &, 267 &, 071 &, 215 & 3,768 &, $\mathbf{0 0 0}$ \\
\hline
\end{tabular}

Dependent variable: Healthcare System and Trust Providers $\quad$ R: $0,415 \quad R^{2: 0,172} \quad$ p:0,000

When Table 11 is examined, it is seen that there is a moderate positive bilateral correlation between physical activity, interpersonal relations, compatibility and vaccination practices, and the role of trust in providers, and when the other variables of the study are taken into consideration, these relationship levels are partially decreased (low level positive correlation). On the other hand, healthy lifestyle behavior together with the sub-dimensions give a moderate and significant relationship with the role of trust in healthcare system and providers in vaccine applications ( $R: 0,463, R^{2}: 0,214$, p: 0,000 ) and $17 \%$ of the total variance is explained at the level of the role of trust in the healthcare system and providers in vaccination practices. 
In Table 12, there are results regarding the effect of healthcare professionals' healthy lifestyle behaviors on the "People Effective on Society" which is one of the sub-dimensions of attitude towards vaccine applications.

Table 12. Healthy Lifestyle Behavior Factors- People Effective on Society Multiple Regression Analysis Results

\begin{tabular}{lccccc}
\hline Variables & $\mathbf{B}$ & Std. Error & $\boldsymbol{\beta}$ & $\mathbf{t}$ & $\mathbf{p}$ \\
\hline (Fix) & 1,686 &, 365 & - & 4,623 &, 000 \\
Health Anxiety &, 340 &, 081 &, 311 & 4,178 & $\mathbf{, 0 0 0}$ \\
Physical Activity &,- 121 &, 059 &,- 134 & $-2,046$ &, $\mathbf{0 4 2}$ \\
Health Responsibility &, 007 &, 073 &, 006 &, 090 &, 929 \\
Spiritual Development &, 078 &, 089 &, 058 &, 878 &, 381 \\
Stress Management &, 056 &, 070 &, 050 &, 793 &, 428 \\
Interpersonal Relations &,- 114 &, 093 &,- 089 & $-1,228$ &, 220 \\
Balanced diet &,- 006 &, 073 &,- 005 &,- 087 &, 931 \\
Compatibility &, 259 &, 076 &, 198 & 3,415 &, $\mathbf{0 0 1}$ \\
\hline
\end{tabular}

Dependent variable: People Effective on Society

When Table 12 is analyzed, it is seen that the role of the importance of the people who have an impact on the society in Health Anxiety, Physical Activity, Compliance and vaccine applications, there is a moderate positive bilateral correlation in bilateral relations, and when the other variables of the research are taken into consideration, these relationship levels are partially decreased (low positive correlation). On the other hand, healthy lifestyle behavior together with the sub-dimensions give a moderate and
R: $0,364 \quad R^{2: 0,132 \quad p: 0,000}$

significant relationship with the role of the people who are influential on the society in vaccine applications (R: 0,364, $\left.\mathrm{R}^{2}: 0,132, \mathrm{p}: 0,000\right)$ and the role of importance of people who are influential on the society in vaccine applications explains $13 \%$ of the total variance.

In Table 13, there are results related to the effect of healthcare professionals' healthy lifestyle behaviors on "Cost" which is one of the sub-dimensions of attitude towards vaccine applications.

Table 13. Healthy Lifestyle Behavior Factors-Cost Multiple Regression Analysis Results

\begin{tabular}{lccccc}
\hline Variables & $\mathbf{B}$ & Std. Error & $\boldsymbol{\beta}$ & $\mathbf{t}$ & $\mathbf{p}$ \\
\hline (Fix) & 1,574 &, 456 & - & 3,449 &, 001 \\
Health Anxiety &, 279 &, 103 &, 203 & 2,701 &, $\mathbf{0 0 7}$ \\
Physical Activity &,- 081 &, 075 &,- 072 & $-1,083$ &, 279 \\
Health Responsibility &,- 009 &, 093 &,- 007 &,- 099 &, 921 \\
Spiritual Development &,- 306 &, 114 &,- 181 & $-2,689$ &, $\mathbf{0 0 8}$ \\
Stress Management &, 028 &, 089 &, 020 &, 315 &, 753 \\
Interpersonal Relations &, 156 &, 118 &, 097 & 1,320 &, 188 \\
Balanced diet &, 167 &, 093 &, 111 & 1,794 &, 074 \\
Compatibility &, 280 &, 095 &, 174 & 2,952 & $\mathbf{0 0 3}$ \\
\hline Dom
\end{tabular}

Dependent variable: Cost $\quad$ R: 0,332

When Table 13 is examined, it is seen that the role of the importance of cost in Health Anxiety, Spiritual Development, Compatibility and vaccine applications is a moderate positive bilateral correlation in bilateral relations, and when other variables of the study are taken into consideration, these relationship levels are partially decreased (low positive correlation). On the other hand, healthy lifestyle behavior together with the sub-dimensions give a moderate and meaningful relationship with the role of cost in vaccine applications (R: 0,332, $\mathrm{R}^{2}: 0,110$, p: 0,000 ) and $11 \%$ of the total variance is explained at the level of role of cost importance in vaccine applications. 


\subsection{Findings on Confirmatory Factor Analysis (CFA)}

In this section, the degree of compliance of the data to the default model was tested by performing CFA on the health literacy and rational drug use scales with the AMOS package program.

\subsubsection{Results of Research Model (Measurement Model)}

It is assumed that variables in the research model; "Health Anxiety, Physical Activity, Health Responsibility, Spiritual Development, Stress Management, Interpersonal Relationships, Balanced Nutrition, Compliance and Risks / Benefits, Communication and Media Tools, Beliefs and
Approaches to Health and Preventive Practices, Role of Healthcare Professionals, Social Norms, Health the system and Providers Trust, Cost, People Effective on Society and causal relationships between these factors can be explained. Confirmatory factor analysis was performed to test the validity of the scales used and the structures of all scales were verified. Since some of the measurement values produced for the test of the validity of the scales are not within the acceptable limits, some modifications proposed by the program have been modified. Details about the measurement model developed are presented below. Confirmatory factor analysis results and goodness of fit values regarding healthy lifestyle behavior and attitude towards vaccine applications are given in Figure 2. 

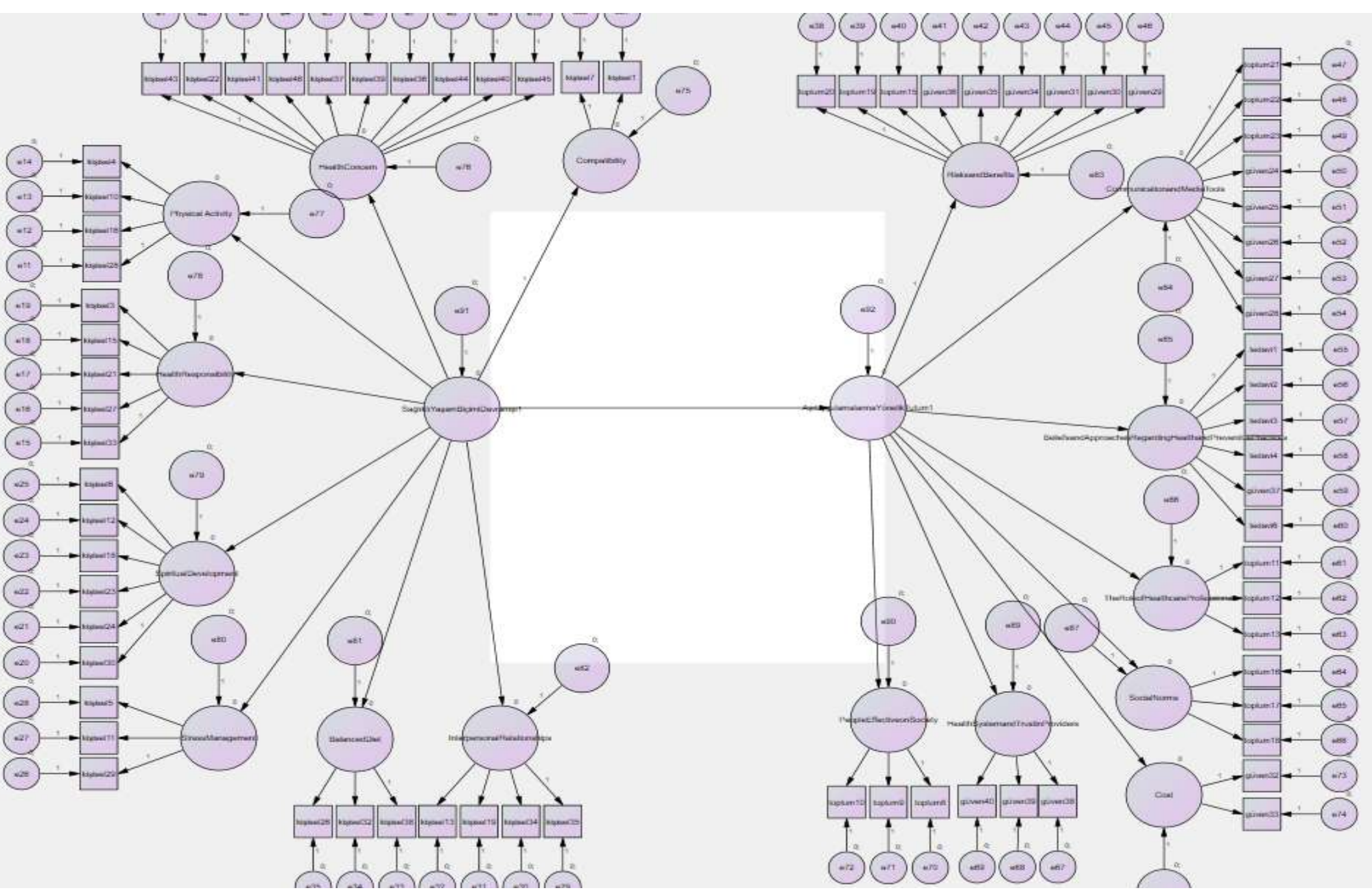

[(X²/df: 3,588; GFI: 0,81; NFI: 0,86; CFI: 0,90; RMSEA: 0,067; Model AIC = 7402,807; Independence AIC = 42117,085;

Model CAIC = 8165,595; Independence CAIC = 42457,321; ECVI: 11,285; ECVI Independence Model = 64,203)]

Figure 2. Healthy Lifestyle Behavior-Vaccine Practices Attitude Research Model (Measurement Model) and Goodness of Fit Results 
By applying Second Level Confirmatory Factor Analysis (CFA) to the corrected measurement model, the degree to which the latent variables can be explained by the observed variables was revealed. In Table 14, the generally accepted goodness fit index values in the literature are shown after the analysis.
Table 14. Measurement Model Goodness of Fit Indices

\begin{tabular}{cccc}
\hline $\begin{array}{c}\text { General } \\
\text { Model } \\
\text { Fit }\end{array}$ & $\begin{array}{c}\text { Good } \\
\text { Fit }\end{array}$ & $\begin{array}{c}\text { Acceptable } \\
\text { Compliance }\end{array}$ & $\begin{array}{c}\text { Compliance } \\
\text { Values } \\
\text { Obtained }\end{array}$ \\
\hline $\boldsymbol{x}^{2} / \mathbf{s d}$ & $\leq 3$ & $\leq 5$ & 3,588 \\
\hline $\boldsymbol{R} \boldsymbol{M S E A}$ & $\leq 0,05$ & $\leq 0,08$ & 0,067 \\
\hline $\boldsymbol{N F I}$ & $\geq 0,95$ & $\geq 0,90$ & 0,86 \\
\hline $\boldsymbol{C F I}$ & $\geq 0,97$ & $\geq 0,95$ & 0,90 \\
\hline $\boldsymbol{I F I}$ & $\geq 0,95$ & $0,94-0,90$ & 0,91 \\
\hline $\boldsymbol{P G F I}$ & $\begin{array}{c}\text { Close } \\
\text { to 1 }\end{array}$ & $\begin{array}{c}\text { Lower limit } \\
\text { value 0,50 }\end{array}$ \\
\hline $\boldsymbol{G F I}$ & $\geq 0,90$ & $0,89-0,85$ & 0,68 \\
\hline
\end{tabular}

As can be seen in Table 15, the results show that the majority of the fit indices of the proposed research model are at an acceptable level of fit.

\section{CONCLUSION AND DISCUSSION}

The main purpose of this study is to examine the relationship between the healthcare professionals' level of showing healthy lifestyle behaviors and their attitudes towards the use of healthcare services. The universe of the research is the middle and / or upper level managers of the general private hospitals operating in the province of Istanbul under the umbrella of the Turkish Ministry of Health Private Health Institutions. In the study in which the quantitative research method (quantitative research design) was used, the data were collected by face-to-face questionnaire technique. The study is descriptive and cross-sectional. The quantitative research method has been used in the study since it is thought that the validity and reliability of the research results can be fully ensured under the consideration of the purpose of the research, the problem of the research and the subject of the research,

As a result of the descriptive statistical analysis, it was observed that the variable of "Compatibility" (Avg: 4,277) has the highest average among healthy lifestyle behavior factors. Similarly, among the attitude factors towards vaccine applications, the highest mean variable was "Beliefs and Approaches to Health and Preventive Practices" (Avg: 4,287).

Gender, age, educational status and occupation of the individuals participating in the research are given as $62 \%$ of the individuals participating in the study are women, $84 \%$ are university graduates, $64 \%$ are middle-age people and are 64,4\% middle-level managers.

According to the results of multiple linear regression analysis in order to determine the relationship between healthy lifestyle behavior and attitude towards vaccine applications; it has been observed that the subdimensions of healthy lifestyle behaviors; Health
Anxiety, Health Responsibility, Balanced Nutrition, Compliance and attitude factors towards vaccine applications have moderate positive bilateral correlation between the Risks / Benefits of vaccine applications, and on the other hand; when the other variables of the study were taken into consideration, these relationship levels were partially decreased (low level positive correlation).

It has been observed that the role of communication and media tools in vaccine applications have a moderate positive bilateral correlation in bilateral relations on health anxiety, balanced nutrition, compatibility and attitude factors towards vaccine applications which are the sub-dimensions of healthy lifestyle behaviors" on the other hand; when other variables of the study are taken into consideration, these relationship levels are partially decreased (low positive correlation).

It has been observed that there is a moderate positive bilateral correlation between the health and preventive practices beliefs and approaches about vaccine applications which are the sub-dimensions of healthy lifestyle behaviors and the health anxiety, interpersonal relations, balanced nutrition, compatibility and attitude factors towards vaccine applications; On the other hand; when other variables of the study are taken into consideration, these relationship levels are partially decreased (low level positive correlation).

It has been observed that there is a moderate positive bilateral correlation between bilateral relations among the sub-dimensions of healthy lifestyle behaviors and the factors of attitude towards spiritual development, balanced nutrition, compatibility and vaccination practices, the role of healthcare workers in vaccine practices, and on the other hand; when other variables of the study are taken into consideration, these 
relationship levels are partially decreased (low positive correlation).

It has been observed that there is a moderately positive bilateral correlation in bilateral relations among health anxiety, health responsibility and attitude factors towards vaccine applications and the role of social norms in vaccination practices, which are the subdimensions of healthy lifestyle behaviors; and on the other hand; when other variables of the study are taken into account, it is seen that these correlation levels are partially reduced (low level positive correlation).

It has been observed that there is a moderately positive bilateral correlation in bilateral relations among physical activity, interpersonal relationships, compatibility and attitude factors towards vaccine applications, the role of trust in healthcare system and providers in vaccination practices which are the subdimensions of healthy lifestyle behaviors; and on the other hand, when other variables of the study are taken into account, these correlation levels are partially reduced (low level positive correlation).

It has been observed that there is a moderate positive bilateral correlation in bilateral relations among Health anxiety, physical activity, compliance and attitude factors towards vaccination applications, the role of the importance of the people who have an impact on the society in vaccine applications which are the subdimensions of healthy lifestyle behaviors; and on the other hand, when the other variables of the study are taken into consideration, these relationship levels are partially decreased (low positive correlation).

According to the confirmatory factor analysis results; it was observed that the fit indices of the proposed research model were at an acceptable level of fit.

It has been observed that there is a moderate positive bilateral correlation in bilateral relations among health anxiety, moral development, compatibility and attitude factors towards vaccine applications, the role of the importance of cost in vaccine applications which are the sub-dimensions of healthy lifestyle behaviors; and on the other hand, when other variables of the study are taken into consideration, it is seen that these relationship levels are partially decreased (low correlation).
In summary, studies have shown that there is a positive relationship between lifestyle and health status, healthcare use and healthcare systems (Fleming and Marshall, 2008). The individual, who transforms healthy lifestyle behaviors into a lifestyle, can maintain his wellbeing and improve his health. Therefore, the development and maintenance of healthy lifestyle behaviors are the foundation of health and disease protection. This situation reveals the importance of practices for the development of life styles, which are the most important factors in the prevention of disease and health promotion (Zaybak and Fadiloğlu, 2004; Ayaz et al., 2005).

\section{Recommendations}

Informing families about the factors causing diseases, explaining how the disease prevention and treatment methods work and comparing their effectiveness can positively affect families' approach to vaccines, accordingly, information and guidance studies should be carried out in this direction.

On the other hand, people who volunteer to vaccinate and rely on vaccination systems may hesitate to vaccinate, in consideration of not being able to afford to pay for the vaccines. It is recommended that the society is informed correctly and regularly by the Ministry of Health in this direction.

At the same time, it is known in the literature that informing families by healthcare professionals increases the rates of vaccination (Babadağl1, 2007). In addition, it has been determined that the knowledge and practices of healthcare professionals affect their own vaccination practices, vaccine recommendations and vaccine scopes (Larson and Karafillakis, 2015). Therefore, it is recommended that healthcare professionals take a positive attitude towards vaccines and vaccination applications and be guided in this direction.

It is recommended to change the idea that the transmission of some vaccine-preventable diseases is necessary for the formation of immunity, or that breastfeeding, traditional / alternative treatment methods are as important as vaccination or more important than vaccination, and the negative attitudes of television and social media tools towards vaccines should be eliminated completely. 


\section{REFERENCES}

\begin{abstract}
Adult Immunization Guide
http://meramtip.com.tr/kalite/dosyalar/rehberler/eriskin-

bagisiklama/EriskinBagisiklamaRehberi.pdf (Date 22.12.2020).

(2016).

Arısoy, E.S., Çiftçi, E., Hacımustafaoğlu, M., Kara, A., Kuyucu, N., Somer, A., et al. (2015). Clinical practical recommendations for Turkish national vaccination schedule for previously healthy children (National Vaccination Schedule) and vaccines not included in the schedule. J Pediatr Inf., 9 (1): 1-11.
\end{abstract}

Ayaz, S., Tezcan, S. and Akıncı, F. (2005). Health promotion behaviors of nursing school students. Cumhuriyet University School of Nursing Journal, 9 (2): 26-34.

Babadağlı F. Vaccine Deficiencies and factors affecting children aged 12-36 months who applied to Yalova State Hospital. Istanbul University Child Health Institute, 2007, Istanbul.

Belloc, N.B. and Breslow, L. (1972). Relationship of physical health status and health practices. Preventive Medicine, 9, 409-421.

Blaxter, M. (1990). Health and Lifestyles. London: Routledge.

Cindaş, A. (2001). General Principles of Exercise Application in the Elderly. Turkey Journal of Geriatrics 2001; 4 (2): 77-84.

Cockerham, W.C. (2014). Health Behavior. Wiley Online Library, https://onlinelibrary.wiley.com/doi/epdf/10.1002/9781118410868.wbe hibs296, https://doi.org/10.1002/9781118410868. wbehibs296

Conner, M. and Norman, P. (1996). (eds.) Predicting Health Behavior. Buckingham, UK: Open University Press.

Conner, M.T. (2015). Health Behaviors. ResearchGate, https://www.researchgate.net/publication/304193514_Health_Behavio rs/link/55f40dfa08ae7a10cf88e63e/download, DOI: 10.1016 / B978-008-097086-8.14154-6.

Eckel, R.H., Jakicic, J.M., Ard, J.D., de Jesus, J.M., Houston Miller N, Hubbard V.S. et al.; American College of Cardiology/American Heart Association Task Force on Practice Guidelines. 2013 AHA / ACC guideline on lifestyle management to reduce cardiovascular risk: a report of the American College of Cardiology / American Heart Association Task Force on Practice Guidelines. J Am Coll Cardiol 2014; 63 (25 Pt B, 25 Part B): 2960-84.

Ferguson, K.J. (1998). Health behavior. Wallace RB. Public Health \& Preventive Medicine. 14th Edition Stamford: Appleton \& Lange, 811816.

Fleming, P., Marshall, G. (2008). Lifestyle interventions in primary care. Systematic review of randomized controlled trials. Can Fam Physician, 54: 1706-1713.
Gochman, D.S. (Ed), (1997). Handbook of Health Behavior Research New York, Vols. 1-4: Plenum.

Kanj, M. and Mitic, W. (2009). Consultants to the Eastern Mediterranean Region, World Health Organization. Health Literacy and Health Promotion Definitions, Concepts and Examplesin the Eastern Mediterranean Region Individual Empowerment Conference Working Document, 16: 1-46.

Karaca, T., Özkan, SA (2016). Examination of the studies conducted using the healthy lifestyle behaviors scale, which is composed of nursing students and nurses: A literature study. JHS 201613 (2): 35883601. doi: 10.14687 / jhs.v13i2.3869.

Knowler, W.C., Barrett-Connor, E., Fowler, S.E., Hamman, R.F., Lachin, J.M., Walker, E.A. et al.; Diabetes Prevention Program Research Group. Reduction in the incidence of type 2 diabetes with lifestyle intervention or metformin. N Engl J Med 2002; 346 (6): 393 403.

Larson H, Karafillakis E. (2015). Vaccine hesitancy among healthcare workers and their patients in Europe: A Qualitative Study, p.1-32, 2015. https://doi.org/10.1016/j.vaccine.2016.08.029

Millen B.E., Abrams S., Adams-Campbell L., Anderson C.A.M., Brenna, J.T. Campbell, W.W. et al. (2016). The 2015 Dietary Guidelines Advisory Committee scientific report: development and major conclusions. Adv Nutr, 7 (3): 438--44.

U.S. Department of Health \& Human Services (2020). Immunization and infectious diseases. http://www.healthypeople.gov/2020/topicsobjectives/topic/immunizati on-andinfectious-diseases, (Date accessed: 22.12.2020).

WHO (2009). State of the World's Vaccines and İmmunization, 3rd Ed. Geneva, World Health Organization.

World Health Organization (WHO). Media Center. Immunization Coverage. Fact sheet [Updated: 2019 Sep; Cited: 2016 Nov 17] Available from: http://www.who.int/mediacentre/factsheets/fs378/en/

Zachariah, J.P. and de Ferranti, S.D. (2013). NHLBI integrated pediatric guidelines: battle for a future free of cardiovascular disease. Future Cardiol, 9 (1): 13-22. doi: 10.2217 / fca.12.72.

Zaybak, A., Fadıloğlu, Ç. (2004). Determining the health promotion behavior of university students and the factors affecting this behavior. Journal of Ege University School of Nursing, 20 (1): 77-95. 